\title{
Project-Based Management Technique for Radiofrequency Spectrum Planning and Allocation Part One: The Business Case
}

\author{
Andrew J Kerans \\ James Cook University \\ Barrie Todhunter \\ University of Southern Queensland
}

\begin{abstract}
Spectrum Management is the regulatory action of defining the use of the radiofrequency spectrum. Often this requires the clearance of a large number of incumbent systems to make way for new technologies such as Fourth Generations Mobile Broadband $(4 \mathrm{G})$. While great economic benefits may be derived from the new technologies the clearance of any band will come at a cost. It is important both costs and benefits be quantified and compared. In many administrations including Australia these processes are carried out without a defined project management structure. In the first of a series of two papers the Authors combine over 40 years of radio systems and planning experience to suggest a methodology for project-based management of spectrum planning activities.
\end{abstract}

Keywords-project based spectrum management;

\section{Introduction}

Spectrum Management is the combination of a number of key fields to produce a 'spectrum product'. The product is the technical and administrative definition of how a particular block (or band) of frequencies may be used. The art of spectrum management draws on the four areas of engineering, allocations, economics and policy to produce the final outcome as shown in Fig. 1 below.

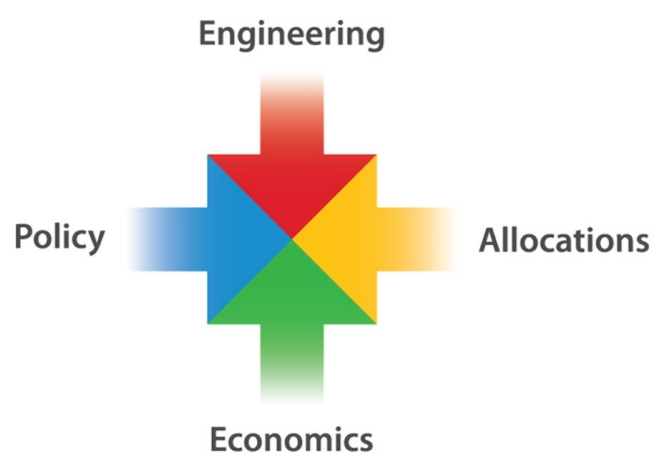

Fig. 1. Skill-sets in the Spectrum Management Process (Kerans 2011) 
Bringing these four areas together within the project environment is a difficult task as each discipline is usually in a separately managed area. Because the technical frameworks behind a block of spectrum and the technologies that define these are resident in the engineering world, engineers tend to be the first to suggest the need for a change of use of a particular band and are the ones who then define the technical parameters. However economists must decide if there is a total net benefit to be gained and policy officers must 'wrap' the spectrum for allocation. This is a complex multi-disciplinary problem requiring expert through-life management. Spectrum Planning as a profession could benefit from a project-based management approach which requires the development of a specific technique suited to the somewhat arcane art of spectrum management. As the first part of this process this paper presents a suggested methodology for the development of the initial spectrum planning business case.

\section{Spectrum management, is it a project?}

First, using the definition from the Project Management Institute (2014) a spectrum planning process can be compared to more common projects (text from PMI in italics):

More specifically, what is a project? It's a temporary group activity designed to produce a unique product, service or result.

A project is temporary in that it has a defined beginning and end in time, and therefore defined scope and resources.

A spectrum management exercise has a defined beginning and end where it comprises the replanning of a band for a new technology. Traditionally it begins when the need for change is first proposed and the consultation process begins, which includes putting the team together and developing the project plan and it ends when the spectrum is reallocated.

... a project is unique in that it is not a routine operation, but a specific set of operations designed to accomplish a singular goal. So a project team often includes people who don't usually work together - sometimes from different organizations and across multiple geographies.

While the inputs to the project are known and the skill-sets well defined, like shipbuilding, in the case of a spectrum planning process they have been brought together to produce a defined objective, the refarming of a particular band or bands. If carried out correctly this process is unlikely to occur again for at least two decades, if at all, thus the project is indeed unique.

And all must be expertly managed to deliver the on-time, on-budget results, learning and integration that organizations need. 
Therefore a spectrum planning exercise meets the PMI criteria and is indeed a project requiring expert management using recognised project management principles.

\section{The spectrum management business case}

A business case is a recommendation to decision makers to take a particular course of action for the organisation, supported by an analysis of its benefits, costs and risks compared to the realistic alternatives, with an expectation of how it can be best implemented (Gambles 2009).

In an average spectrum planning exercise the actual planning team including engineers, policy analysts and economists will rarely exceed ten people, so with associated overheads such as travel the 'hard' costs of a project management exercise will rarely be significant when compared with the economic impact of the project.

This paper therefore concentrates on the 'soft' and 'hard' costs and skills associated with a successful spectrum management process and the 'sale' of that process to the decisionmakers as the key stakeholders who will eventually decide whether it proceeds or otherwise.

\section{The 'hard' costs of a spectrum project}

In developing a business case spectrum planning engineers must present the facts as they stand along with the hard and soft costs. The hard costs can be simply stated as the number of full time equivalent (FTE) personnel that will be needed for the project. Assuming an 'average' overhead for each FTE the hard cost of the project can be defined. This is then the opportunity cost lost to potential other spectrum projects in undertaking the project being presented and this opportunity can be taken into account by the decision makers.

\section{The 'soft' costs of a spectrum project}

The soft costs of a spectrum planning exercise are much harder to define. In the case of mobile broadband; the sought after bands are generally between $500 \mathrm{MHz}$ and $4.2 \mathrm{GHz}$. None of these bands is unused and many are home to a significant amount of installed and operating equipment. The cost to retune or in many cases abandon or completely replace this equipment must be estimated along with the value of any lost services to the economy.

On the other side of the ledger both the return to government from the sale or lease of the spectrum should be combined with an estimation of the additional economic benefit that will be derived from the new use.

In Australia the spectrum regulator is the Australian Communications and Media Authority (the ACMA). The ACMA is a world leader in spectrum management and is well advanced in 
defining the economic decision that are needed in spectrum planning. In its 'Principles for Spectrum management" and in many spectrum consultations the ACMA states:

"In determining what actions maximise the public benefit, the ACMA uses a Total Welfare Standard (TWS). The application of a TWS enables the ACMA to adhere to a consistent conceptual framework when assessing the public interest impact of any regulatory proposals it considers. A TWS requires consideration of the total benefit (economic surplus) of a regulatory decision. The approach that results in the greatest net benefits is regarded as the approach that best promotes the public interest. The impact of a decision on particular groups should be evaluated as part of the analysis, but issues associated with the distribution of benefits and costs between different parties should be addressed as a separate and distinct policy question.

In formulating proposals and ultimately deciding on future arrangements in the band in future stages of the review, the ACMA will consider the costs and benefits associated with any potential changes in line with a TWS” (ACMA 2009).

\section{Lobbying: the greatest risk of failure}

Associated with a large installed equipment base is the potential for political lobbying, particularly when large influential users such as the Defence Department of the broadcasting industry is affected. In any modern spectrum planning exercise this represents the greatest risk to the project and may even see a viable project fail due to political influence or intervention.

This should be addressed as a high risk in the risks and opportunities section of the business case along with a thorough and convincing mitigation strategy.

The mitigation of this particular risk will be of particular interest to all government decision makers and indeed their political masters. The only true mitigation will consist of a thorough and well prepared and articulated communications strategy based on a sound business case.

\section{A spectrum communications strategy}

Traditionally in Australia the communications strategy has consisted of a number of consultation papers aimed at gathering the information required to make an informed decision on change. However as spectrum access becomes more fraught with more and more systems being affected by the seemingly insatiable demand for mobile broadband, both the economic analysis and the communications strategy should now be developed prior to the commencement of the project and presented in the business case. 
A spectrum planning communications strategy will need to be two-pronged. One avenue of communication should be dedicated to openly informing incumbent operators and potential beneficiaries of the change of the processes and the outcomes of an economic analysis of the project. Communication should be open and honest and feedback should be verified and where a change is suggested, that change made or the suggestion taken into account.

The second avenue of communications should be to management, politicians and the general public. In a democratic society politicians will try to do what is best for as much of the community as possible. So if a positive message is sold to the public, this will benefit the political process and provide a buffer to any possible political intervention.

The public will want to know what they get from the project, for example faster mobile broadband, and will need to understand how what they lose (if anything) will be replaced.

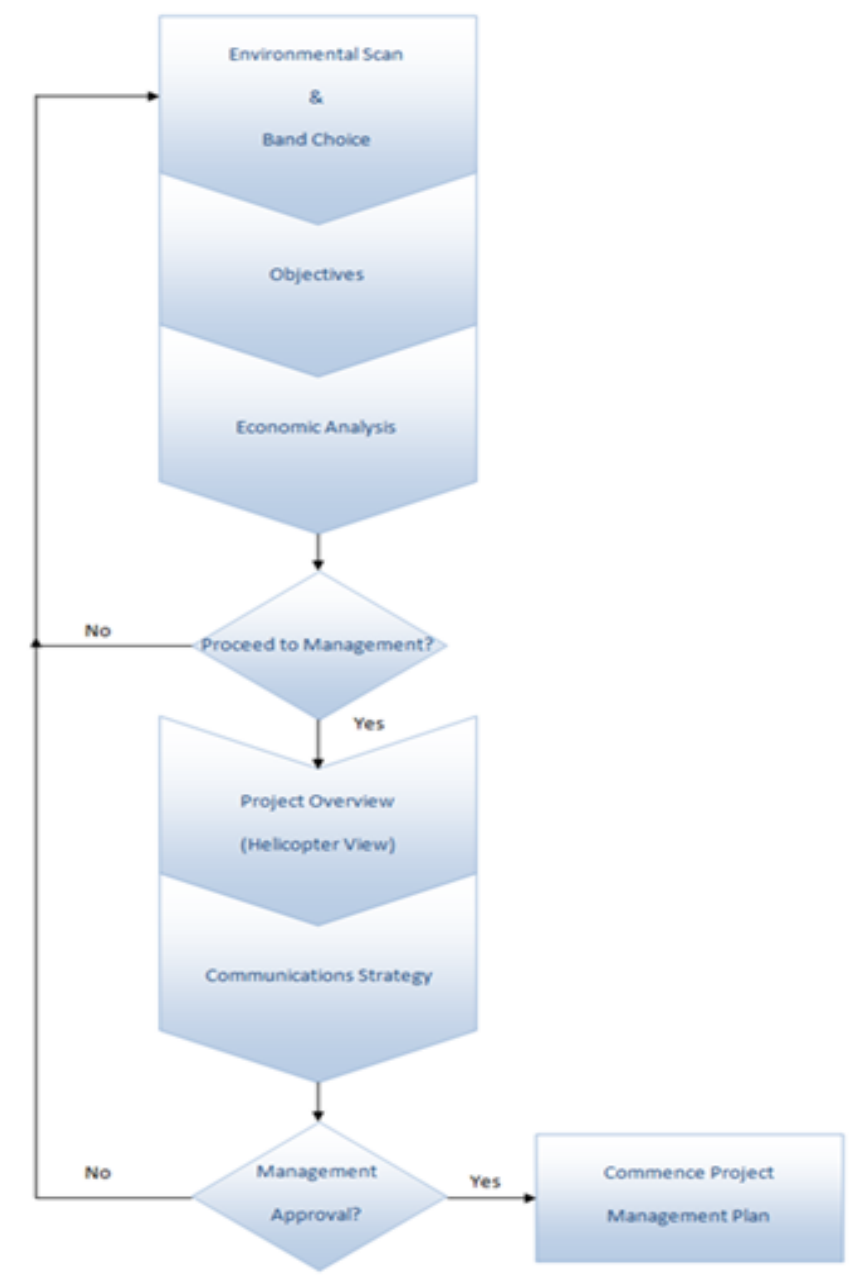

Fig. 2. Spectrum Management Business Case Process (Authors) 


\section{Selling the project- a suggested process}

The spectrum planning business case should present information in an easy to follow manner with reasons, costs, risks and strategies well laid out and documented in a way that all levels of management can understand. This is particularly important in engineering or spectrum projects which are usually engineering based.

The first piece of information a decision maker will want about the proposed change is 'why?' To address this, the project manager must define the mission, what is the objective and the timeframe over which the project is expected to run?

The second part of the answer to 'why?' is the economic appraisal or the cost benefit analysis of the project taking into account actual costs (costs of equipment and return to government) as well as the overall economic cost or benefit using a methodology that takes into account real benefits such as income from the sale of the spectrum and resulting from its use as well as public good benefits (such as the loss or provision of a capability in a public service entity such as police or defence).

Assuming the economic ledger is favorable and the project return is greater than other projects seeking access to limited resources, the project manager should recommend that the project proceed but that management should examine the risks and mitigating factors.

\section{The risk analysis, telling it like it is}

The risk analysis must be an honest and forthright presentation of any major risks to the success of the project, and particularly those that could cause actual or reputational harm to people, politicians or the regulator. Opportunities would also be identified as part of the risk analysis as they are seen as positive risk events rather than those with negative outcomes.

A major risk to any spectrum management process, providing the engineering work is thorough and peer reviewed, is likely to be the risk of political intervention (Chirgwin 2012). As previously discussed the mitigation strategy is a thorough communications strategy combined with open and honest consultation.

Other risks that may be addressed include the risks that the economic analysis was flawed or that elements were omitted. If this were to be the case incumbents would discover it and that would be evident in their lobbying.

Another risk may be that the environment was not properly scanned and the band chosen is not the best band for the purpose. This would result in a bespoke spectrum arrangement which would not attract the economies of scale evident in a harmonised approach. 
The plans of other countries or regions should be considered. There is a risk that even if the right band is chosen, a plan developed prematurely or in isolation may not be widely adopted, again affecting the cost of equipment and the ability of users to roam internationally.

There are many other risks and the entire (proposed) project team along with any other identified expertise should be brought together to identify risks and mitigation strategies and decide if they warrant inclusion in the business case. However while some risks may be insignificant no real risk should be ignored or omitted as without a strategy the project may suffer and the project manager held to account.

Each risk should be paired with a strategy to combat it commensurate with the likelihood of it happening or the outcome if it did. A common risk management matrix is useful in this exercise. (See for example (DMO Liability Risk Management Process)

\section{Strategies for success}

In this element the basic strategies that the project team will use to ensure a successful outcome should be presented. At the business case stage these should be well considered but need not be fully developed.

Examples of strategies would be the number and purpose of each consultation stage, where the project would be re-evaluated in an iterative process and any particular strategic elements to the overall communications strategy reviewed based on the responses to each stage.

Strategies to 're-home' displaced systems should be considered at this stage as co-mitigation along with an effective communications plan. There is also the potential for compensation, either directly or indirectly via incentive auctions (see for example Cramton 2011), which may mitigate the risk of stakeholder opposition.

This is also a time for individual milestones to be identified and any initial plans to deal with slippage and float presented.

What is known as a 'helicopter view' of the entire project from inception to allocation should also be presented as a part of this stage so that the decision-makers can see the use of resources over time and gain an understanding of when certain risk elements may require special attention.

These elements are combined in the business case development process pictorially described in Figure 2. This process also defines two 'decision points' at which a decision is made whether to proceed to the next stage or otherwise. 


\section{Go or no-go? - The business case decision making criteria}

Using Fig. 2 as a guide we can step through the proposed spectrum business case flowchart. In a spectrum management process certain bands are allocated to certain services in the International Telecommunication Union (Radiocommunications Sector, ITU-R) table of allocations (ITU 2012). This table is generally reflected in each Administration in a similar document, for example in the Australian Radiofrequency Spectrum Plan (ACMA 2013). This is at a high level the first indicator that a band may be suited to a new use.

Beyond that there need to be standards to support equipment manufacture. In mobile telephony there are a number of these, such as those made by the '3rd Generation Partnership Program' (3GPP). This is the first step in ensuring economies of scale and thus economic return. The final stage is harmonisation to enhance economies of scale and enable device roaming. This is vital as a 'bespoke' spectrum arrangement can isolate an Administration.

Once a band has been chosen the final arrangements may be suggested or work may be needed to negotiate them internationally. Regardless at this stage the objectives of the process should be set and tested against an economic analysis (or cost benefit analysis). At this stage the effects of various allocation techniques, such as incentive auctions, can be tested.

Of course the entry of a new technology need not be based on clearance of the old. Where sharing is possible this should be explored. However sharing spectrum means that an element of risk is passed to both the incumbent and new entrant and in this scenario the opportunity cost of this risk needs to be analysed.

Now the economic analysis described in section 5 should be undertaken and at this stage the project sponsor should, based on the outcome of the analysis, decide if the development of the business case should proceed and be taken to management for decision.

If the decision is made not to proceed, but spectrum is still required the environmental scan should recommence and the same process followed.

If the economic analysis suggests the project should proceed a helicopter view of the project should be developed outlining the basis of the project management plan, the risk analysis and the outcome of the economic analysis.

At this stage the combined stakeholder management plan and communication strategy should also be developed and presented, along with the helicopter view, to management for final approval. 
A loop back to environmental scan is shown at this stage, assuming management approval is not given. However non-approval may be due to a number of factors and a return to environmental scan should only be taken if the reason for refusal was the band choice. In many cases simple adjustment to the economic analysis, risk analysis or communications plan may seal approval at a second pass.

If approval is given to proceed, a full project management plan (PMP) should be developed which incorporates elements of the business case, stakeholder engagement plan, risk analysis and communications plan. Resource implications, timelines and project flow should be examined in the PMP. Management may or may not wish to examine the full PMP prior to final go ahead, and this decision will most likely hinge on the risk analysis and mitigation strategies presented as part of the business case.

\section{Conclusions}

Spectrum is an increasingly valuable natural resource which best serves society when allocated to the highest value use (ACMA 2009). However with the increase in demand for mobile broadband empowered by portable devices such as the ubiquitous 'smart phone' (Deloitte 2014), access is becoming more and more challenging. Decisions by regulators will in the future be potentially challenged by adversely-affected stakeholders and the ability of the regulator to make decisions that are fully defensible will depend on thorough project management planning and implementation. Alternatively decisions to not make change may be challenged by proponents of new technologies and again the ability of a regulator to regulate will be weakened.

Spectrum access is becoming increasingly difficult as new mobile technologies vie for access to bands where existing, often stationary systems are already deployed. In addition as entities such as public safety agencies realise that spectrum access is being exhausted they vie for access to blocks that they see will meet their needs into the future, often using emotive arguments rather than substantiated facts (Police Federation 2013).

Even where an incumbent is not required to move, but just accept more risk of interference via sharing a thorough project based management process may both alleviate political and regulatory processes and calm the nerves of the incumbents.

Pressure from incumbents may drive increased political scrutiny of spectrum management in the future. In order to mitigate political intervention, senior management within individual regulators is likely to require through cost benefit analysis, risk analysis and stakeholder management plans prior to committing to the refarming of a band for new uses. However provided these are undertaken diligently and the reasons for change made evident 
the political process should realize that change is the right option for economic development and allow the regulator to undertake its task unhindered.

This paper has outlined a suggested business case development method which may gain sponsor support and lead to project approval. Hopefully this method could streamline processes through a Westminster style regulatory process and lead to more efficient and timely release of spectrum for new technologies. The development of the various parts of a spectrum project management plan will be dealt with in subsequent papers.

\section{References}

3rd Generation partnership Program (3GPP) www.3gpp.org

ACMA. 2009. Principles for spectrum management. Australian Communications and Media Authority. Available at:

http://www.acma.gov.au/webwr/_assets/main/lib310828/principles_for_spectrum_mana gement.pdf

ACMA. 2013. Australian Radiofrequency Spectrum Plan, available at http://www.acma.gov.au/ /media/Spectrum\%20Transformation\%20and\%20Government/ Information/pdf/Australian\%20Radiofrequency\%20Spectrum\%20Plan\%202013.pdf

Chirgwin, R. 2012. Minister intervenes in Oz spectrum auction. The Register 20 November 2012. http://www.theregister.co.uk/2012/11/20/conroy_to_set_spectrum_reserve_price/

Cramton, P. 2011. Incentive Auctions. University of Maryland, April 2011. Available at: http://www.cramton.umd.edu/papers/spectrum/

Defence Materiel Organisation. Office of Special Counsel. Liability Risk Management Process. www.defence.gov.au/dmo/Multimedia/LRA_Process-9-4067.pdf accessed $13 / 12 / 2012$

Deloitte Access Economics. 2014. Mobile nation. The economic and social impacts of mobile technology. Report for the Australian Mobile Telecommunications Association. Available at: http://www.amta.org.au/pages/State.of.the.Industry.Reports

Gambles, I. 2009. Making the Business Case. Page 1. Gower Publishing 2009. ISBN 978-0566-08745-5.

International Telecommunications Union. 2012. The ITU Radio Regulations. . Downloadable from: http://www.itu.int/pub/R-REG-RR-2012

Kerans, A. 2011. Radio Spectrum Planning, Does it Matter in Industry? Presentation to IEEE North Qld Section November 2011. Available from author at andrew.kerans@acma.gov.au 
Police Federation of Australia. 2013. Submission to the Joint Inquiry into Public Safety Mobile Broadband, June 2013. Available from:

http://www.aph.gov.au/Parliamentary_Business/Committees/Joint/Law_Enforcement/Completed_i nquiries/2010-13/spectrummobilebroadband/report/index

Project Management Institute. 2014. 'What is project management'. From http://www.pmi.org/About-Us/About-Us-What-is-Project-Management.aspx, accessed $17 / 12 / 2012$ 